\title{
Anti-atherogenic Potential of Natural Honey: Anti-diabetic and Antioxidant Approaches
}

\author{
Mina Hemmati ${ }^{1}$, Mehdi Karamian ${ }^{2}$ and Mohammad Malekaneh ${ }^{1}$ \\ 1. Department of Biochemistry, School of Medicine, Birjand University of Medical Sciences, Birjand 999067, Iran \\ 2. Hepatitis Research Center, School of Medicine, Birjand University of Medical Sciences, Birjand 999067, Iran
}

\begin{abstract}
Atherogenic dyslipidemia is a major risk factor for cardiovascular disease in patients with DM and characterized with high level of lipoprotein (a) ( $\mathrm{pp}$ (a)) and low level of adiponectin. Adiponectin serves as a regulator in glucose and lipid metabolism therefore is essential for maintaining response to insulin. Lp (a) is a cholesterol rich compound, so agents with hypoglycemic properties are suitable for treatment of diabetes that could improve atherogenic dyslipidemia. The major goal of this study was to investigate antioxidant capacity of natural honey as well as levels of adiponectin, Lp (a) and AIP (atherogenic index of plasma) in honey treated experimental diabetes. Twenty eight streptozotocin-induced diabetic male wistar rats were randomized into four groups (seven animals each) and administered distilled water, natural honey 1 and $2 \mathrm{~g} / \mathrm{kg}$ and glibenclamide. After three weeks treatment, adiponectin, Lp (a), MDA (malondialdehyde), FBS (fasting blood sugar), TG (triglyceride), cholesterol, HDL-C (high density lipoprotein) and LDL-C (low density lipoprotein) were measured. AIP also was calculated. Data analysis showed that honey significantly reduced serum level of triglycerides $(0.72 \pm 0.02 \mathrm{mmol} / \mathrm{L})$ and FBS $(7.8 \pm 0.12 \mathrm{mmol} / \mathrm{L})$ to normoglycemic levels in diabetic rats. Honey also significantly increased serum adiponectin $(4.5 \pm 0.26 \mathrm{mg} / \mathrm{L})$ and HDL-C $(0.72 \pm 0.14 \mathrm{mmol} / \mathrm{L}) \mathrm{levels}$ in diabetic rats. Serum level of LP (a) was declined in honey treated groups $(25.5 \pm 3.2 \mathrm{~g} / \mathrm{dL})$. Also honey supplementation decreased MDA level and AIP to normoglycemic control group. Our study supports the hypothesis that honey has beneficial effects in diabetes by its anti-atherogenic effect. Increased adiponectin level in honey treated groups might be associated with better glycemic control and improved lipid profile. Accordingly agents that increase adiponectin levels might be valuable targets for decreasing the atherogenic risk in diabetes.
\end{abstract}

Key words: Adiponectin, atherogenic index of plasma, diabetes, honey, lipid profile.

\author{
Abbreviations \\ AIP $=$ atherogenic index of plasma \\ $\mathrm{DM}=$ diabetes mellitus \\ FBS $=$ fasting blood sugar \\ FRAP $=$ Ferric reducing antioxidant power \\ HDL-C $=$ high density lipoprotein-cholesterol \\ LDL-C $=$ low density lipoprotein-cholesterol \\ $\operatorname{Lp}(\mathrm{a})=$ lipoprotein (a) \\ MDA $=$ malondialdehyde \\ $\mathrm{TG}=$ triglyceride
}

\section{Introduction}

DM (diabetes mellitus) is an important global public health problem with increasing incidence [1]. Based on both experimental and clinical studies;

Corresponding authors: Mina Hemmati, Ph.D., assistant professor, research field: biochemistry. E-mail: minahemmati@bums.ac.ir. oxidative stress plays a pivotal role in the pathogenesis and/or complications of DM [2]. Oxidative damage has been suggested to be a contributory factor in the development and complications of diabetes [3]. It is also known that MDA (malondialdehyde), the principal product of polyunsaturated fatty acid peroxidation, is a highly toxic aldehyde. MDA is commonly regarded as a biomarker of lipid peroxidation [4]. Lipid peroxide mediated tissue damages have been observed in the development of type I and type II DM [5]. Therefore, hypoglycemic agents that could improve lipid profile and ameliorate oxidative stress are good candidates for preventing diabetic complications. In recent years there has been renewed interest in the use of plant derivatives as antidiabetic compounds $[6,7]$. 
Flavonoids are naturally occurring phenolic compounds that are widely distributed in plants. Due to the presence of aromatic hydroxyl groups, flavonoids have strong antioxidant properties. They are scavengers of reactive oxygen and nitrogen species and, therefore, inhibit peroxidation reactions [8]. Honey is a natural substance with a high content of phenolic compounds which has been used in various medicinal traditions throughout the world, but its metabolic effects have not been thoroughly explored [9]. In the last few years, there has been renewed interest in research that investigates the potential health benefits of natural honey in the management of various diseases, its including cardio-protective [10], hepato-protective, hypoglycaemic [11], antioxidant [12] and antihypertensive effects [13].

As evidence has shown, honey supplementation significantly reduced blood glucose concentrations in diabetes model rats [14]. Furthermore, the consumption of natural honey has been shown to reduce plasma glucose, triglycerides and cholesterol in persons with and/or without diabetes [15].

Recent findings indicate that adiponectin (adipokine from white adipose tissue) serves as a regulator in the expression of key hepatic genes in glucose and lipid metabolism, essential for maintaining response to insulin [16]. Adiponectin is emerging as a protein with insulin-sensitizing, anti-inflammatory and anti-apoptotic functions. Cardiovascular disease is one of the most important complications of DM, and dyslipidemia is one of the major risk factors for cardiovascular disease in DM, so amelioration of cardiovascular risk factor such as LDL-cholesterol particles, lipid peroxide and lipoprotein (a) (Lp (a)) could lead to better treatment of diabetes. Lp (a) is a cholesterol-rich compound in human plasma with plasminogen-like fragments and is considered as a thrombogenic and an atherogenic factor [17] and recent studies were reported a high plasma levels of Lp (a) in diabetic patient [18].
According to several studies on the role of adiponectin in regulating blood sugar, and considering cardiovascular problems in diabetes patients, the current study aimed to investigate antidiabetic and anti-atherogenic effects of honey in male wistar rats.

\section{Materials and Methods}

\subsection{Experimental Animals}

Experimental subjects were 35 adult male wistar derived rats, 200 to $220 \mathrm{~g}$, bred and raised at the university animal quarters. Diabetes was induced by intra peritoneal administration of streptozotocin (60 $\mathrm{mg} / \mathrm{kg}$ body mass) (Sigma Aldrich, USA) in rats fasted for 16 hours two weeks prior to the initiation of treatments. The animals were divided randomly into five groups $(n=7)$ : (a) Non diabetes control rats received distilled water $(0.5 \mathrm{~mL})$, (b) diabetes control rats received distilled water $(0.5 \mathrm{~mL})$, (c) and (d) diabetes model rats administered honey $1 \mathrm{~g}$ and $2 \mathrm{~g} / \mathrm{kg}$ body mass, respectively and positive control group, (e) diabetes rats administered glibenclamide $0.6 \mathrm{mg} / \mathrm{kg}$. Honey and distilled water were administered orally once daily for 3 weeks. Honey sample considered in this study was from jujube plant area, that provided by local beekeepers living in south khorasan, Iran, during the 2013 year flowering. All animal care and experimental procedures were performed according to the rules of ethical standards laid down in the 1964 Declaration of Helsinki and its later amendments and were approved by the local Ethics Committee.

\subsection{Biochemical Studies}

At the end of experimental period, the rats were sacrificed under chloroform anesthesia. Blood samples were collected in centrifuge tubes without anticoagulants and allow clotting. The clotted blood was then centrifuged at $3000 \mathrm{rpm}$ for $20 \mathrm{~min}$. Serum was transferred into new tubes and stored at $-20{ }^{\circ} \mathrm{C}$ until further analysis. Serum FBS, triglycerides, total cholesterol, and high-density lipoprotein cholesterol (HDL-C) were assessed using colorimetric kits from 
Pars Azmun (Tehran, Iran). Non-HDL-C was calculated by subtracting HDL-C from total cholesterol. AIP (Atherogenic index of plasma) was calculated according to the following equation: $\mathrm{AIP}=$ $\log$ (TG/HDL-C) with units for TG and HDL-C in $\mathrm{mmol} / \mathrm{L}$.

\subsection{TBARS (Thiobarbituric Acid Reactive Substances)}

\section{Measurement}

Blood was collected from the heart in the end of treatment period and used for measurement of MDA (malondialdehyde). The level of MDA was measured by the thiobarbituric acid reactive substances method [19]. Plasma samples $(300 \mu \mathrm{L})$ were added to $3 \mathrm{ml}$ thiobarbituric acid reactive substances reagent $(7.5 \mathrm{~g}$ trichloroacetic acid, $187 \mathrm{mg}$ TBA and $6.25 \mathrm{ml} \mathrm{HCL})$. The mixture warmed for $20 \mathrm{~min}$ in boiling water bath and finally, the absorbance of samples was determined at $532 \mathrm{~nm}$.

\subsection{FRAP (Ferric Reducing Antioxidant Power) Assay}

The FRAP assay, according to the previous studies [20], was used to evaluate total antioxidant power in the serum of the different groups mentioned above. Antioxidant power in the samples reduced ferric to ferrous iron at low $\mathrm{pH}$ levels and led to the formation of a colored ferrous-tripyridyltriazine complex. The intensity of the colored complex was monitored at 593 nm. $2 \mathrm{ml}$ of FRAP reagent consisting of $300 \mathrm{mM}$ sodium acetate buffer ( $\mathrm{pH}$ 3.6), 10 mM TPTZ (2,4,6-tris (2-pyridyl)-S-triazine) solution in HCL, and $20 \mathrm{mM} \mathrm{FeCl} 3$. $6 \mathrm{H}_{2} \mathrm{O}$ solution in a proportion of 10:1:1 (v/v) was added to $50 \mu \mathrm{L}$ of sample. After 15 min, the absorbance at $593 \mathrm{~nm}$ was read.

\subsection{Quantitative Determination of Lp (a) and Adiponectin in Rat Serum}

Adiponectin and Lp (a) concentrations in the rat serum were determined using ultrasensitive ELISA kits for rat adiponectin (Catalog \# 90060) and rat Lp (a) ELISA Kit (Catalog \# 80570) from Crystal Chem, respectively. The manufacturer's protocols were followed for both assays.

\subsection{Statistical Analysis}

All the Data were expressed as mean \pm standard error of three replicates for seven rats in each group. Data were analyzed by one-way ANOVA using SPSS version 16 software (SPSS Inc., Chicago, IL, USA). A $P$-value $<0.05$ was considered statistically significant.

\section{Results}

Table 1 summarizes the results of serum FBS, triglycerides, total cholesterol, HDL-C, non-HDL-C and AIP observed in the different groups of rats at the end of the 3-week treatment period. The serum FBS concentration in the diabetic control rats was significantly higher $(31.1 \pm 2.3 \mathrm{mmol} / \mathrm{L})$ than that in the non-diabetic control rats $(8.3 \pm 0.25 \mathrm{mmol} / \mathrm{L})$. On the other hand, treatment with honey $(1$ and $2 \mathrm{~g} / \mathrm{kg}$

Table 1 Effects of honey on serum FBS, triglycerides, total cholesterol, HDL-C, Non-HDL-C and AIP (atherogenic index of plasma) in streptozotocin-induced diabetes rats.

\begin{tabular}{lllllll}
\hline $\begin{array}{l}\text { Experimental } \\
\text { groups }\end{array}$ & FBS $(\mathrm{mmol} / \mathrm{L})$ & $\begin{array}{l}\text { Triglycerides } \\
(\mathrm{mmol} / \mathrm{L})\end{array}$ & $\begin{array}{l}\text { Total cholesterol } \\
(\mathrm{mmol} / \mathrm{L})\end{array}$ & HDL-C $(\mathrm{mmol} / \mathrm{L})$ & $\begin{array}{l}\text { Non-HDL-C } \\
(\mathrm{mmol} / \mathrm{L})\end{array}$ & AIP \\
\hline $\begin{array}{l}\text { Non-diabetic } \\
\begin{array}{l}\text { Control } \\
\text { Diabetic Control }\end{array}\end{array}$ & $8.3 \pm 0.25^{2 \mathrm{a}}$ & $0.6 \pm 0.04^{\mathrm{a}}$ & $1.58 \pm 0.11^{\mathrm{a}}$ & $0.9 \pm 0.12^{\mathrm{a}}$ & $0.66 \pm 0.11^{\mathrm{a}}$ & $-0.17 \pm 0.012^{\mathrm{a}}$ \\
$\begin{array}{l}\text { Diabetic }+ \text { Honey } \\
(1 \mathrm{gm} / \mathrm{kg})\end{array}$ & $7.8 \pm 0.12^{\mathrm{a}}$ & $2.05 \pm 0.2^{\mathrm{b}}$ & $2.74 \pm 0.31^{\mathrm{b}}$ & $0.4 \pm 0.21^{\mathrm{b}}$ & $2.1 \pm 0.14^{\mathrm{b}}$ & $+0.45 \pm 0.021^{\mathrm{b}}$ \\
$\begin{array}{l}\text { Diabetic }+ \text { Honey } \\
(2 \mathrm{gm} / \mathrm{kg})\end{array}$ & $9.03 \pm 0.15^{\mathrm{a}}$ & $0.76 \pm 0.03^{\mathrm{a}}$ & $1.57 \pm 0.13^{\mathrm{a}}$ & $0.84 \pm 0.11^{\mathrm{a}}$ & $0.78 \pm 0.13^{\mathrm{a}}$ & $-0.04 \pm 0.012^{\mathrm{a}}$ \\
$\begin{array}{l}\text { Glibenclamide } \\
(0.6 \mathrm{mg} / \mathrm{kg})\end{array}$ & $8.5 \pm 0.46^{\mathrm{a}}$ & $0.62 \pm 0.12^{\mathrm{a}}$ & $1.68 \pm 0.17^{\mathrm{a}}$ & $0.92 \pm 0.09^{\mathrm{a}}$ & $0.76 \pm 0.16^{\mathrm{a}}$ & $-0.19 \pm 0.022^{\mathrm{a}}$ \\
\hline
\end{tabular}

1 For details of experimental conditions see the text. 2 Data are expressed as mean \pm SD of 5 rats in each group. In each column, figures bearing different superscripts are significantly different at $P \leq 0.05$ (one way ANOVA). 
body mass) significantly decreased the FBS levels $(7.8 \pm 0.12 \mathrm{mmol} / \mathrm{L}$ and $9.03 \pm 0.15 \mathrm{mmol} / \mathrm{L}$, respectively) in the diabetes model rats.

Similarly, the serum triglycerides, total cholesterol, and non-HDL-C concentrations were significantly higher in the diabetic control rats, when compared with those in the non-diabetic control rats. However, treatment with honey significantly decreased the serum triglycerides, total cholesterol, and non-HDL-C levels, with values almost similar to those noted in the non-diabetic control rats. Based on the results in table 1, AIP significantly correlated with diabetes and honey supplementation decreased AIP to normoglycemic control group.

Table 2 shows the effects of honey on the body weight of the control and honey-treated rats. As shown in the table, the diabetic groups treated with honey exhibited an increased in the body weight $(P<$
0.05), with values approximately similar to those observed in the non-diabetic control rats.

To determine role of honey supplementation in lipid peroxidation process, MDA assay was performed. As shown in Fig. 1, the higher level of lipid peroxidation in diabetic control group has decreased in diabetic rats fed honey.

Fig. 2 shows that the honey-fed rats (1 and $2 \mathrm{~g} / \mathrm{kg}$ body mass) had significantly higher adiponectin levels (4.5 \pm 0.2 and $4.2 \pm 0.3 \mathrm{mg} / \mathrm{L}$, respectively), when compared with the diabetic control rats $(2.3 \pm 0.1$ $\mathrm{mg} / \mathrm{L})$. Effects of honey on level of $\mathrm{Lp}$ (a) was summarized in Fig. 3.

Serum Lp (a) level was significantly higher in the diabetes rats than in the normal rats $(\mathrm{P}<0.05)$. After three weeks of treatment with honey and glibenclamide, Lp (a) level was decreased in all the treated groups (Fig. 3).

Table 2 Effects of honey on body weight of diabetic rats.

\begin{tabular}{|c|c|c|c|c|c|}
\hline $\begin{array}{l}\text { Experimental }^{\mathrm{a}} \text { groups } \\
\text { Parameters }\end{array}$ & $\begin{array}{l}\text { Non-diabetic } \\
\text { Control }\end{array}$ & Diabetic Control & $\begin{array}{l}\text { Diabetic + Honey } \\
(1 \mathrm{gm} / \mathrm{kg})\end{array}$ & $\begin{array}{l}\text { Diabetic + Honey } \\
(2 \mathrm{gm} / \mathrm{kg})\end{array}$ & $\begin{array}{l}\text { Glibenclamide }(0.6 \\
\mathrm{mg} / \mathrm{kg})\end{array}$ \\
\hline Initial body wt (gm) & $225 \pm 9^{2 a}$ & $235 \pm 10^{\mathrm{a}}$ & $228 \pm 11^{\mathrm{a}}$ & $230 \pm 8^{a}$ & $238 \pm 10^{\mathrm{a}}$ \\
\hline Final body wt (gm) & $240 \pm 8^{2 a}$ & $170 \pm 13^{\mathrm{b}}$ & $205 \pm 14^{\mathrm{a}}$ & $212 \pm 9^{\mathrm{a}}$ & $246 \pm 12^{\mathrm{a}}$ \\
\hline
\end{tabular}

${ }^{1}$ For details of experimental conditions see the text.

${ }^{2}$ Data are expressed as mean $\pm \mathrm{SD}$ of 5 rats in each group. In each row, figures bearing different superscripts are significantly different at $P \leq 0.05$ (one way ANOVA).
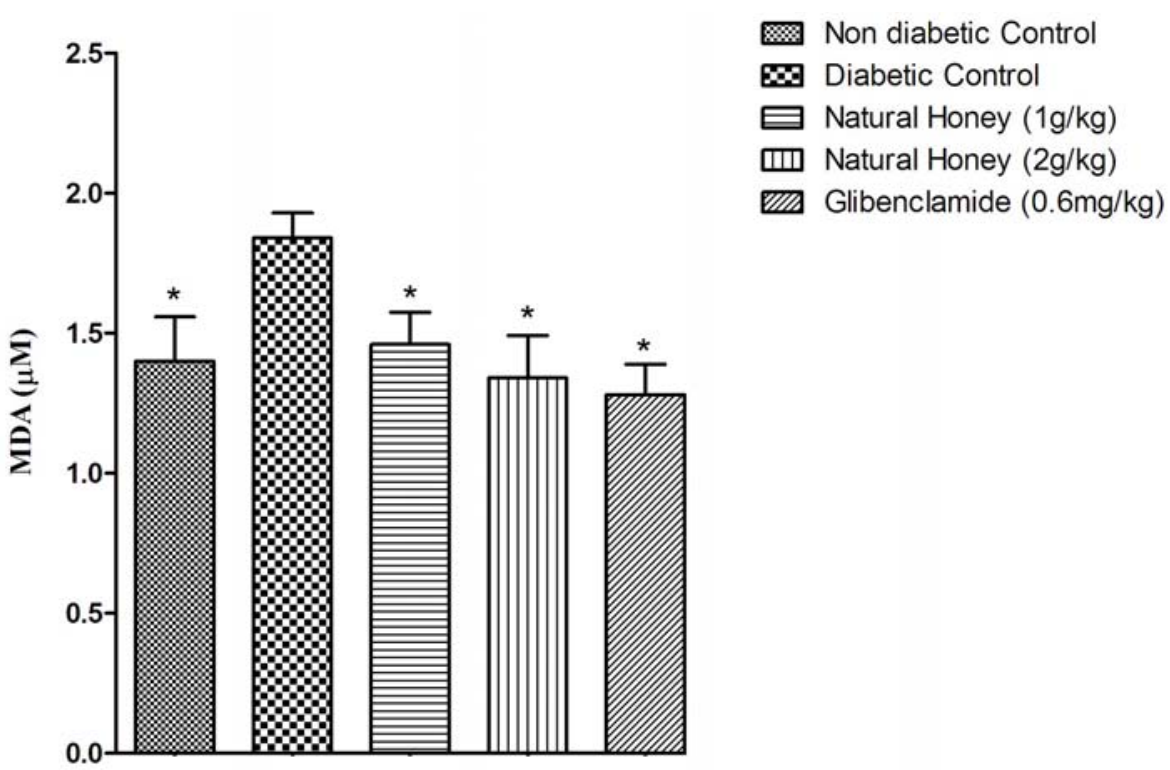

Fig. 1 Serum MDA (malondialdehyde) concentration of rats fed by honey diet.

Data are expressed as mean $\pm \mathrm{SD}$. Values are statistically significant at $* P \leq 0.05$ compared to diabetes control. 
Non-diabetic Control

$\$$ Diabetic Control

曰 Honey $(1 \mathrm{~g} / \mathrm{kg})$

띠 Honey $(2 \mathrm{~g} / \mathrm{kg})$

mas Glibenclamide $(0.6 \mathrm{mg} / \mathrm{kg})$

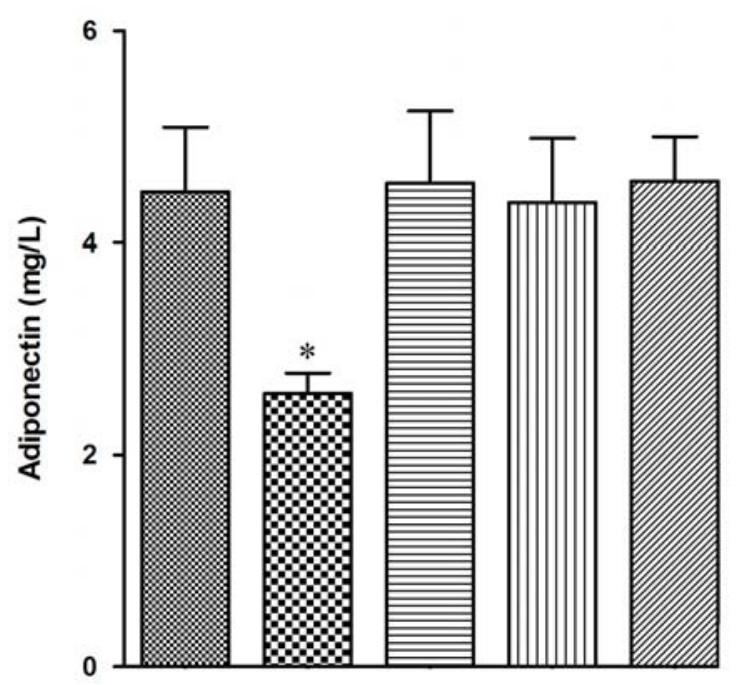

Fig. 2 Serum adiponectin concentrations of rats fed by honey diet.

Data are expressed as mean $\pm \mathrm{SD}$. Values are statistically significant at $* P \leq 0.05$ compared to non-diabetes control.

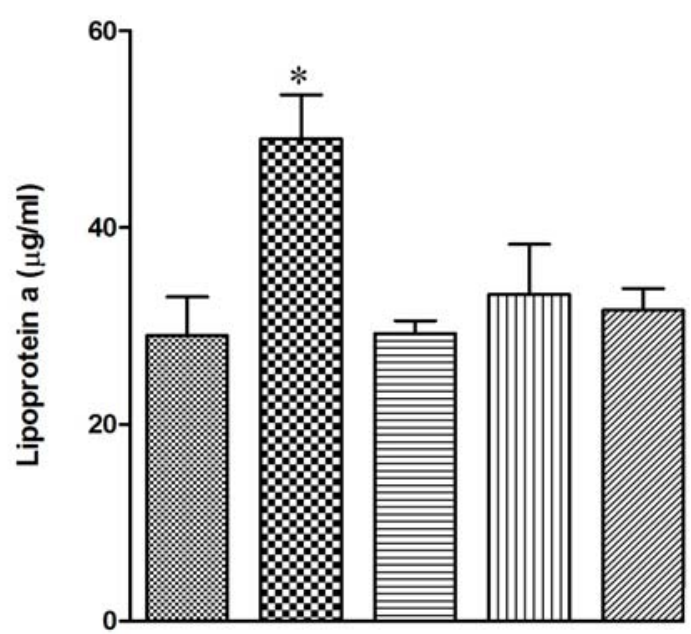

Non-diabetic Control

$\infty$ Diabetic Control

$\square$ Honey $(1 \mathrm{~g} / \mathrm{kg})$

而 Honey $(2 \mathrm{~g} / \mathrm{kg})$

III Glibenclamide $(0.6 \mathrm{mg} / \mathrm{kg})$

Fig. 3 Serum Lp(a) concentrations of rats fed by honey diet.

Data are expressed as mean $\pm \mathrm{SD}$. Values are statistically significant at $* P \leq 0.05$ compared to non-diabetes control.

Fig. 3 shows that the honey-fed rats $(1$ and $2 \mathrm{~g} / \mathrm{kg}$ body mass) had significantly lower Lp (a) levels (25.5 \pm 3.2 and $22 \pm 1.3 \mathrm{~g} / \mathrm{dL}$, respectively), when compared with the diabetic control rats $(55 \pm 7.4$ $\mathrm{g} / \mathrm{dL})$.

\section{Discussion}

The data presented here showed that the oral administration of honey could improve lipid profile as well as adiponectin level in diabetes model rats, and significantly reduced their FBS levels to normal (Table 1). Based on the literature, experimental animals with low adiponectin levels are high risk in the development of insulin resistance and diabetes [21]. Kobuta et al. found that adiponectin-deficient mice showed insulin resistance [21]. Interestingly this group showed impaired glucose-lowering effect of insulin in adiponectin-deficient mice despite having 
normal insulin level [21].

Given the significant increase in adiponectin levels in diabetes model rats treated with honey (Fig. 2), the reduction of blood sugar may be associated with this hormone. Studies have shown that oxidative stress has a major role in the pathogenesis of diabetes [22]. Based on previous studies; honey has an anti-radical power and significant antioxidant activity [23-25]. It can be estimated that the antioxidant properties of honey may be directly due to reducing free radicals, or indirectly due to increasing the amount of antioxidants present in the target cell. Adiponectin, a circulating hormone secreted by adipose tissue, is considered to modulate oxidative stress, leading to antidiabetic effects [26, 27]. The data obtained from our study showed that honey reduce oxidative stress-mediated lipid peroxidation via decrease in MDA level.

Based on the literature, adiponectin promotes insulin sensitivity, decreases inflammation and promotes cell survival [28]. Holland et al. showed that adiponectin enhances anti-apoptotic metabolite-sphingosine-1-phosphate, which is a potent inducer of proliferation and inhibitor of apoptosis [28]. This hormone is able to regulate the transcription of genes involved in glucose and lipid metabolism [29].

In a study by Liu et al., the mRNA expression levels of some rate-limiting enzymes in glucose and the lipid metabolic pathways of adiponectin knockout mice significantly reduced compared to wild-type ones [16].

Thus, the reduction in serum adiponectin levels in turn appears to impair glucose and lipid metabolism, and insulin resistance occurs. In the present study, honey was able to significantly increase adiponectin level in diabetes model rats. Interestingly, oral administration of honey played an effective role in improvement of body weight loss in diabetic rats; this may be due to accumulation of adipose tissue.

\section{Conclusions}

This study reveals that, honey could be considered an anti-atherogenic factor due to its Lp (a) and AIP lowering effects in diabetic rats. It is likely that honey improved the glucose and lipid metabolism by increasing adiponectin level and/or by reducing oxidative stress-mediated lipid peroxidation in diabetes model rats. Thus, it can be concluded that honey has the ability to reduce complications resulting from diabetes, such as atherosclerosis. Nevertheless, further research is needed to explore the role of honey in the treatment of DM.

\section{Acknowledgments}

This investigation was supported by Grant No. 711 from the office of Vice Chancellor for Research, Birjand University of Medical Sciences.

\section{References}

[1] Shawm, J. E., Sicree, R. A. and Zimmet, P. Z. 2010. "Global Estimates of the Prevalence of Diabetes for 2010 and 2030." Diabetes Res. Clin. Pract. 87: 4-14.

[2] Maritim, A. C., Sanders, R. A., and Watkins, J. B. 2003. "Diabetes, Oxidative Stress, and Antioxidants: A Review." J. Biochem. Mol. Toxicol. 17: 24-38.

[3] Pari, L., and Latha, M. 2005. "Antidiabetic Effect of Scoparia Dulcis: Effect on Lipid Peroxidation in Streptozotocin Diabetes." Gen. Physiol. Biophys. 24: 13-26.

[4] Del-Rio, D., Stewart, A. J., and Pellegrini, N. 2005. “A Review of Recent Studies on Malondialdehyde as Toxic Molecule and Biological Marker of Oxidative Stress." Nutr. Metab. Cardiovasc Dis. 15: 316-28.

[5] Feillet-Coudray, C., Rock, E., Coudray, C., Grzelkowska, K., Azais-Braesco, V., and Dardevet, D. 1999. "Lipid Peroxidation and Antioxidant Status in Experimental Diabetes." Clinica Chimica Acta. 284: 31-43.

[6] Pari, L., and Saravanan, G. 2002. "Antidiabetic Effect of Cogent db, A Herbal Drug in Alloxan Induced Diabetes Mellitus." Comp. Biochem. Physiol. C. Toxicol. Pharmacol. 131: 19-25.

[7] Saravanan, G., Pari, L., and Venkateswaran, S. 2002. "Effect of Cogent Db, a Herbal Drug, on Plasma Insulin and Hepatic Enzymes of Glucose Metabolism in Experimental Diabetes.” Diabetes Obes. Metab. 4: 394-8.

[8] Fuhrman, B., and Aviram, M. 2001. "Flavonoids Protect LDL from Oxidation and Attenuate Atherosclerosis." Curr. Opin. Lipidol. 12: 41-8.

[9] Wang, J., and Li, Q. X. 2011. "Chemical Composition, Characterization, and Differentiation of Honey Botanical 
and Geographical Origins." Adv. Food Nutr. Res. 62: 89-137.

[10] Erejuwa, O. O., Sulaiman, S. A., and Wahab, M. S. 2012. "Honey-A Novel Antidiabetic Agent." Int. J. Biol. Sci. 8: 913-34.

[11] Rakha, M. K., Nabil, Z. I., and Hussein, A. A. 2008. "Cardioactive and Vasoactive Effects of Natural Wild Honey against Cardiac Malperformance Induced by Hyperadrenergic Activity." J. Med. Food 11: 91-8.

[12] Erejuwa, O. O., Gurtu, S., Sulaiman, S. A., Ab-Wahab, M. S., Sirajudeen, K. N., and Salleh, M. S. 2010. "Hypoglycemic and Antioxidant Effects of Honey Supplementation in Streptozotocin-Induced Diabetic Rats.” Int. J. Vitam Nutr. Res. 80: 74-82.

[13] Erejuwa, O. O., Sulaiman, S. A., Wahab, M. S., Salam, S. K., Salleh, M. S., and Gurtu, S. 2011. "Comparison of Antioxidant Effects of Honey, Glibenclamide, Metformin, and Their Combinations in the Kidneys of Streptozotocin-Induced Diabetic Rats." Int. J. Mol. Sci. 12: 829-43.

[14] Erejuwa, O. O., Sulaiman, S. A., Ab-Wahab, M. S., Sirajudeen, K. N., Salleh, S., and Gurtu, S. 2012. "Honey Supplementation in Spontaneously Hypertensive Rats Elicits Antihypertensive Effect via Amelioration of Renal Oxidative Stress." Oxid. Med. Cell Longev 2012: 374037.

[15] Al-Waili, N. S. 2004. "Natural Honey Lowers Plasma Glucose, C-Reactive Protein, Homocysteine, and Blood Lipids in Healthy, Diabetic, and Hyperlipidemic Subjects: Comparison with Dextrose and Sucrose." J. Med. Food 7: 100-7.

[16] Liu, Q., Yuan, B., Lo, K. A., Patterson, H. C., Sun, Y., and Lodish, H. F. 2012. "Adiponectin Regulates Expression of Hepatic Genes Critical for Glucose and Lipid Metabolism." Proc. Natl. Acad. Sci. 109: 14568-73.

[17] Rhoads, G. G., Dahlen, G., Berg, K., Morton, N. E., and Dannenberg, A. L. 1986. "Lp (a) Lipoprotein as a Risk Factor for Myocardial Infarction.” JAMA 256: 2540-4.

[18] Levitsky, L. L., Scanu, A. M., and Gould, S. H. 1991. "Lipoprotein (a) Levels in Black and White Children and Adolescents with IDDM." Diabetes Care 14: 283-7.

[19] Yagi, K. 1976. “A Simple Fluorometric Assay for Lipoperoxide in Blood Plasma." Biochem. Med. 15: 212-6.

[20] Benzie, I. F., and Strain, J. J. 1996. "The Ferric Reducing Ability of Plasma (FRAP) as a Measure of "Antioxidant Power": The FRAP Assay.” Anal. Biochem. 239: 70-6.

[21] Kubota, N., Terauchi, Y., Yamauchi, T., Kubota, T., Moroi, M., Matsui, J., Eto, K., Yamashita, T., Kamon, J.,
Satoh, H., Yano, W., Froguel, P., Nagai, R., Kimura, S., Kadowaki, T., and Noda, T. 2002. "Disruption of Adiponectin Causes Insulin Resistance and Neointimal Formation." J. Biol. Chem. 277: 25863-6.

[22] Kadenbach, B., Ramzan, R., and Vogt, S. 2009. "Degenerative Diseases, Oxidative Stress and Cytochromec Oxidase Function." Trends Mol. Med. 15: 139-47.

[23] Akbulut, M., Ozcan, M. M., and Coklar, H. 2009. "Evaluation of Antioxidant Activity, Phenolic, Mineral Contents and Some Physicochemical Properties of Several Pine Honeys Collected From Western Anatolia." Int. J. Food Sci. Nutr. 60: 577-89.

[24] Al-Hindi, R. R., Bin-Masalam, M. S., and El-Shahawi, M. S. 2011. "Antioxidant and Antibacterial Characteristics of Phenolic Extracts of Locally Produced Honey in Saudi Arabia." Int. J. Food Sci. Nutr. 62: 513-7.

[25] Rodríguez-Malaver, A. J., Rasmussen, C., Gutiérrez, M. G., Gil, F., Nieves, B., and Vit, P. 2009. "Properties of Honey from Ten Species of Peruvian Stingless Bees." Nat. Prod. Commun. 4: 1221-6.

[26] Katsuki, A., Suematsu, M., Gabazza, E. C., Murashima, S., Nakatani, K., Togashi, K., Yano, Y., Adachi, Y., and Sumida, Y. 2006. "Increased Oxidative Stress Is Associated with Decreased Circulating Levels of Adiponectin in Japanese Metabolically Obese, Normal-Weight Men with Normal Glucose Tolerance." Diabetes Res. Clin. Pract. 73: 310-4.

[27] Nakanishi, S., Yamane, K., Kamei, N., Nojima, H., Okubo, M., Kohno, N. 2005. "A Protective Effect of Adiponectin against Oxidative Stress in Japanese Americans: The Association Between Adiponectin or Leptin and Urinary Isoprostane." Metabolism 54: 194-9.

[28] Holland, W. L., Miller, R. A., Wang, Z. V., Sun, K., Barth, B. M., Bui, H. H., Davis, K. E., Bikman, B. T., Halberg, N., Rutkowski, J. M., Wade, M. R., Tenorio, V. M., Kuo, M. S., Brozinick, J. T., Zhang, B. B., Birnbaum, M. J., Summers, S. A., and Scherer, P. E. 2011. "Receptor-Mediated Activation of Ceramidase Activity Initiates the Pleiotropic Actions of Adiponectin." Nat. Med. 17: 55-63.

[29] Yoon, M. J., Lee, G. Y., Chung, J. J., Ahn, Y. H., Hong, S. H., and Kim, J. B. 2006. "Adiponectin Increases Fatty Acid Oxidation in Skeletal Muscle Cells by Sequential Activation of AMP Activated Protein Kinase, p38 Mitogen-Activated Protein Kinase, and Peroxisome Proliferator Activated Receptor Alpha." Diabetes 55: 2562-70. 